Síntese - Rev. de Filosofia

v. 37 N. 117 (2010): 27-44

\title{
A FUNÇÃO DO MÉTODO DE ANÁLISE NA CONSTITUIÇÃO DO ARGUMENTO DO COGITO NAS MIEDTACOÕES: UMA LEITURA DO COGITO VA REDUCTIO AD ABSURDUM
}

(The function of the analytic method in the constitution of the cogito argument in the Meditations: a reading of the cogito via reductio ad absurdum)

Érico Andrade M. de Oliveira *

Resumo: Considerando que o cogito possa ser tomado nas Meditações como a conclusão de uma demonstração, pode-se avançar a tese que essa demonstração está consoante ao método analítico, que Descartes reconhece empreender nesse texto. Esse método teria entre suas funções nas Meditações aquela de apresentar - sob a forma de uma rede de implicações ontológicas - o raciocínio que conduz à certeza da existência. Como cumpre no referido texto determinar a certeza da existência sem tomar como base nenhuma certeza preestabelecida, o método analítico forneceria, segundo nossa interpretação, uma reconstrução do argumento do cogito sob uma base indireta, mais precisamente através de uma reductio ad absurdum, cujo objetivo consiste em mostrar a contradição inelutável na tentativa de um indivíduo de provar a sua não existência.

Palavras-chave: Cogito, Meditações, demonstração, reductio ad absurdum e método analítico.

Abstract: If, in the Meditations, the cogito can be taken as the conclusion of a demonstration, it is possible to advance the thesis that such a demonstration is developed according to the analytical method Descartes admitted having employed in his Meditations. Among its many functions, this method would have that of presenting - in the form of a network of ontological implications -

\footnotetext{
"Professor do Departamento de Filosofia do Centro de Filosofia e Ciências Humanas da Universidade Federal de Pernambuco. Artigo submetido a avaliação no dia 23/02/2009 e aprovado para publicação no dia 27/07/2009.
} 
the reasoning that brought the certainty of existence. When Descartes wrote the Meditations, he intended to prove the certainty of the self-existence without taking into account any previous certainty. Therefore, according to our understanding, the analytical method seems to be the only one that can respond to this exigency since it is able to reconstruct the argument of the cogito in an indirect way, namely through a reductio ad absurdum, of which the goal consists in showing the inevitable contradiction in the attempt to prove one's nonexistence.

Key-words: Cogito, Meditations, demonstration, reductio ad absurdum, analytical method.

\section{Introdução}

literatura secundária frequentemente minimiza a distinção entre
os enunciados do cogito apresentado no Discours de la Méthode
(je pense donc je suis. AT, VI, p. 33) e aquele apresentado nas Meditationes (ego sum, ego existo. AT, VII, p.25) sob a alegação que ambos enunciados apontam para uma equivalência ontológica - pensar implica ser - inscrita, por seu turno, na estrutura ontológica do sujeito pensante ${ }^{1}$. A ausência de distinção entre os dois argumentos incide sob a compreensão da estrutura metodológica que porta o argumento descrito nas Meditações, pois, se o método analítico fora empreendido nessa obra - como atestam diversos textos cartesianos - no intuito de sanar as insuficiências metodológicas da argumentação desenvolvida no Discurso, entre elas aquela referente ao cogito, cumpre pôr em evidência o papel deste método na elaboração daquele argumento a fim de compreender em que medida a estrutura metodológica das Meditações imprime uma formulação inédita e singular do cogito cartesiano $^{2}$. Nessa perspectiva, tentaremos redesenhar a estrutura metodológica do argumento do cogito, exposto nas Meditações, em função do método de análise, desenvolvido nas Regras e na Segunda Objeção.

\footnotetext{
1 AT, VII, p.351. AT, X, p. 140. Toda citação das obras de Descartes será realizada seguindo a notação universal: AT (iniciais dos organizadores), volume e página. Eventualmente citaremos a edição de Alquié: FA (iniciais do organizador), volume e página. A informação bibliográfica completa constará no fim do texto. Todas as citações da edição de AT serão postas conforme a grafia atual. Todas as traduções serão nossas. Doravante designaremos as obras de Descartes pela primeira palavra que compõe o seu título em português. Sobre a compreensão de uma estrutura argumentativa similar entre os textos do Discurso e das Meditações, Forlin sublinha que a ênfase cartesiana no eu penso permanece em ambos os textos e justifica uma estrutura argumentativa similar. Ver: FORLIN, E. O papel da dúvida metafísica na constituição do cogito. São Paulo: Humanitas, 2004. O cuidadoso trabalho do professor Eneias Forlin não leva em consideração a diferença de método empregada por Descartes nas duas obras mencionadas, para a qual o presente trabalho se volta.

${ }^{2}$ Descartes reconhece a falta de precisão do Discurso nos seguintes textos: AT, VII, p.7; particularmente sobre a linguagem empreendida para elaborar os argumentos do texto: AT, VII, p.247 // AT, IX, p.191.
} 
Ainda que a relação entre o método de análise e a ordem empregada na arquitetura das Meditações já tenha sido alvo de importantes interpretações desse texto, insistimos que essas interpretações de maneira geral não puseram em evidência a relação específica desse método com o argumento do cogito. Assim, procuraremos enfatizar no presente artigo o emprego do método analítico nas Meditações na intenção de defender que o referido método subsidia uma prova indireta do cogito através de uma reductio ad absurdum.

Diante das várias interpretações do referido argumento, optamos em analisar aquela deferida por Hintikka por dois motivos: inicialmente porque ela concebe a distinção dos enunciados das Meditações e do Discurso sob a forma de uma exigência cartesiana em precisar a relação, posta de maneira pouca clara no Discurso, entre ser e pensar; uma vez que nesta obra se poderia considerar, entre outras coisas, que o pensamento produz ou é a causa da existência; quando na verdade a existência do indivíduo está subordinada, segundo o próprio Descartes, à existência de Deus (AT, VII, p. 45$)^{3}$. Segundo, no intuito de conceber o cogito enquanto um speech-act, Hintikka ${ }^{4}$ demarca os limites de uma leitura inferencial do cogito - o que

\footnotetext{
${ }^{3}$ A crítica kantiana ao enunciado do cogito, exposta no primeiro paralogismo da razão, está centrada na substancialização da ação de pensar. Ainda que Kant reconheça, na unidade sintética da apercepção transcendental, que o eu penso deve acompanhar todas as representações, enquanto função lógica que sintetiza a diversidade dessas representações num conceito, ele desautoriza que a constituição de um sujeito empírico, enquanto fundamento de todas as representações, possa ser deduzida desta unidade lógica do eu penso. Além disso, há um problema de ordem metodológica na maneira de proceder cartesiana, segundo Kant, não se pode determinar a consciência do eu empírico, suprimindo o conteúdo das representações, como se a razão pura pudesse ter consciência da sua própria existência sem a mediação das intuições a priori do tempo e espaço. A dificuldade aqui consiste no falso pressuposto de que a consciência de si, enquanto unidade lógica da síntese da diversidade das representações, pode ser adquirida sem as representações empíricas, como parece sugerir Descartes através da dúvida hiperbólica, a qual esvazia o conteúdo do pensamento para lhe conceber enquanto substância em si. Para Kant a proposição "eu penso" quando transcreve a necessidade da existência, ultrapassa as condições formais, inscritas na intuição a priori do tempo, de toda experiência possível para refugiar-se na coisa em si, que não poderia ser objeto da razão senão na forma de paralogismos. Cf. KANT, I. Crítica da Razão Pura. Lisboa, Fundação Calouste Gulbenkian, 1997, b414-423. Notadamente Kant não leva em consideração a diferença do enunciado do cogito das Meditações em relação àqueles do Discurso e dos Princípios os quais de fato são transcritos, diferentemente das Meditações, na forma da proposição; eu penso, logo existo. Por isso temos dificuldades em saber se a crítica kantiana se dirige ao cogito enunciado por Leibniz e Wolff (que transcrevem a certeza da existência conforme ela foi exposta no Discurso) ou àquele enunciado nas Meditações.

${ }^{4} \mathrm{O}$ rigor e importância do artigo do Hintikka podem ser constatados, em certa medida, por sua longa vida, visto que após quarenta anos de sua publicação, ele persiste ainda como uma referência obrigatória na interpretação tocante ao cogito, fato esse que podemos constatar nas suas últimas republicações Cf. Publicado originalmente : Cogito ergo sum: inference or performance. In The Review of Philosophy, 1962, p.50-65; HINTIKKA, J. Cogito ergo sum: inference or performance. In Critical Assessments, 1991, p.162-185. Republicado em francês: Cogito ergo sum comme inférence et performace. In Révue de Métaphysique et Morale, n.1, 2000, p. 3-13. Nossa análise fará referência à publicação no Critical Assessements.
} 
inviabilizaria tomá-lo como conseqüência de um raciocínio dedutivo - em dissonância aguda face à tese central deste artigo que sustenta uma leitura dedutiva do cogito 5 .

Nosso artigo comportará três etapas: 1 Exposição e crítica dos argumentos de Hintikka 2 Apresentação da relação do método de análise com a reductio ad absurdum 3 Leitura do cogito mediante uma reductio ad absurdum. Enfim, concluiremos que cogito nas Meditações inscreve-se de forma singular na metafísica cartesiana por fornecer a única prova indireta da existência daquele que pensa.

\section{Dos limites da análise inferencial à compreensão performática: o argumento do cogito como uma inconsistência existencial}

$\mathrm{O}$ artigo de Hintikka Cogito ergo sum: inference or performance forneceu um novo horizonte de interpretação referente à provável estrutura empreendida no argumento do cogito na medida em que ele pôs em evidência a análise performática como ponto cardinal para compreensão deste enunciado. $\mathrm{O}$ epicentro de sua interpretação centra-se numa certa ênfase dada ao dêitico eu cuja referencialidade não poderia, segundo Hintikka, ser verificada senão por meio de uma compreensão performática, ou seja, à proporção que Descartes estaria acentuando o eu no entails (assimilação implicativa) da existência, ele estaria eliminando uma leitura do seu argumento cuja elaboração implicasse uma transposição do cogito para a terceira pessoa. Uma leitura lógico-inferencial tangenciaria, por conseguinte, um certo anacronismo por um lado, indiferente à insistência cartesiana sob o papel central do eu no proferimento eu existo e, por outro, distante da compreensão intuitiva do cogito, apregoada pelo próprio Descartes, segundo Hintikka, à exaustão.

Na intenção de desfazer as interpretações dedutivas do cogito Hintikka lança mão de argumentos, diríamos, lógicos e históricos. Do ponto vista

\footnotetext{
${ }^{5}$ A partir das sugestões de Weiberg e Carney, Hintikka reconsidera parte dos seus argumentos, sem, contudo, pôr em questão sua tese que sustenta uma leitura do cogito cartesiano por meio de um ato performático; expresso na proposição $E u$ não existo, que implica uma contradição performativa. Diferentemente do seu primeiro artigo, Hintikka afirma que uma leitura performativa do cogito não implica a negação de uma leitura inferencial. Pelo contrário, o cogito pode ser compreendido sob aquelas duas óticas, mas insiste que a compreensão do cogito como uma ato-de-fala é mais coerente com o projeto cartesiano (das Meditações) de instaurar a certeza referente àquele elemento da metafísica por meio de um ato de intuição. Cf. HINTIKKA, J. Cogito, Ergo Sum as an Inference and Performance. In The Philosophical Review V.72 n.4, 1963, p.487-496 (ver: p.489).
} 
lógico, a generalização do enunciado: eu penso, logo existo desembocaria numa petitio principii que poderia ser transcrita, ainda segundo Hintikka, do seguinte modo: Todo indivíduo que afirma existir, pensa, mas só pode pensar quem existe, pois a afirmação da existência está condicionada ao ato de pensar da mesma maneira que o ato de pensar está condicionado à existência ${ }^{6}$. Além disso, uma vez que se suprime o dêitico eu do enunciado do cogito, incorre-se num outro erro de natureza lógica; considerando que a proposição geral de que todo ser que pensa existe não implica que um eu singular exista. Desse modo, a consciência da dúvida empreendida por um eu singular acerca da sua própria existência é condição necessária para o anúncio da existência de um ser pensante particular no que consiste essencialmente o objetivo do enunciado cartesiano. Sem a consciência da dúvida o indivíduo não pode jamais saber que pensa nem muito menos que existe, ainda que seja certa a proposição: para pensar é necessário existir.

As críticas de caráter histórico são incisivas e defendem, sobretudo, uma estrita negação da leitura do cogito sob um viés dedutivo. O ponto central do argumento de Hintikka é transpor a assertiva cartesiana quanto à desautorização de uma leitura silogística do cogito para uma negação de toda forma de inferência enquanto estrutura lógica do referido argumento $^{7}$. Ainda segundo Hintikka, eclipsar-se-ia, com uma leitura inferencial do cogito, a pretensão cartesiana de tomar a existência enquanto uma intuição cuja função consistiria no reconhecimento imediato da indissociabilidade dos atos de ser e de pensar, naquele que afirma sua própria existência ${ }^{8}$.

Assim, a tomada do cogito sob uma estrutura dedutiva, por um lado, negligenciaria o papel do dêitico eu no entails da existência - a existência de um eu singular é condição para o proferimento da existência - à proporção que, por outro, distanciaria o ato de ser daquele de pensar; dado que esses atos seriam tomados como esferas distintas que se seguem uma da outra, em dissonância, portanto, com a intenção cartesiana em enfatizar a existência enquanto pressuposto e condição para o proferimento, empreendido por um eu, relativo à afirmação da sua própria existência. Desse modo, a intuição do cogito constituir-se-ia, segundo Hintikka, na consciência imediata da indissociabilidade, no $e u$, do ato de pensar daquele de existir?.

\footnotetext{
${ }^{6}$ HINTIKKA, J. Cogito ergo sum: inference or performance. In Critical Assessments, 1991, p. 162-185, p.173.

7 HINTIKKA, J. Cogito ergo sum: inference or performance. In Critical Assessments, 1991, p. 162-185, p.165-170.

${ }^{8}$ Por isso, argumenta Hintikka, a hesitação de Descartes em empregar o termo ergo nas Meditações, que poderia sugerir falsamente, como acontece do Discurso, o emprego de um certo raciocínio para aquisição da certeza da existência

9 HINTIKKA, J. Cogito ergo sum: inference or performance. In Critical Assessments, 1991, p. $162-185$, p. 165.
} 
A inviabilidade lógica e, sobretudo, histórica de conceber o cogito sob uma estrutura inferencial lastrearia uma interpretação pragmática do enunciado cartesiano como única forma de explicar o caráter intuitivo da certeza da existência. $\mathrm{O}$ recurso à análise pragmática passa pela assimilação da teoria dos atos de fala, segundo a qual a verificação de uma proposição, tomada neste caso como um proferimento, está condicionada à verificação da ação do emissor no mundo; considerando-se, desse modo, que a situação do emissor, no contexto no qual fora realizado o proferimento, é imprescindível à compreensão do próprio proferimento ${ }^{10}$. O proferimento eu existo tem como referência aquele que a emite, de sorte que ele se constitui como um proferimento autorreferencial, diferenciando-se, por conseguinte, de proferimentos como Sócrates existe, que fazem referência a um objeto que não pode ser autoverificado, uma vez que a sua verificação depende da existência de um indivíduo que não é o emissor do proferimento. A particularidade do proferimento eu existo deve-se, portanto, ao fato de ser ele construído sobre uma base performática em que o sujeito da ação faz referência a si mesmo. Nesse caso, o sujeito da ação - representado pelo dêitico eu - não pode ser desconsiderado quanto à análise da significação do proferimento sob risco deste proferimento perder o seu sentido; a sua referencialidade ${ }^{11}$.

Nessa perspectiva, Hintikka inverte o enunciado cartesiano eu existo, seguindo a sugestão da Segunda Meditação, transcrevendo-o de forma negativa através do proferimento eu não existo ${ }^{12}$. Como se trata de um ato-defala, inscrito na primeira pessoa, ele se refere àquele que o profere. Desse modo, a verificação deste proferimento pressupõe a existência do emissor, uma vez que ele está posto na primeira pessoa. Nesse caso, sua autorreferencialidade só não poderia ser realizada mediante a não existência daquele que profere esse enunciado. Sendo assim, a verificabilidade do proferimento eu não existo jamais pode ser possível uma vez que a existência do emissor é sempre um pressuposto para sua declaração. Essa

\footnotetext{
${ }^{10}$ Ao contrário do positivismo lógico, que restringe a verificabilidade da validade de uma proposição: por um lado à sua constituição lógico-sintática e, por outro, à sua correspondência aos fatos no mundo, a análise performática estende o campo semântico de um enunciado ao contexto no qual ele fora proferido. A distinção entre a verificação da validade da proposição segundo a análise performática em relação àquela da análise lógica ou mesmo àquela da verificação empírica, empreendidas pelo positivismo lógico, é traçada por Austin, introdutor da teoria dos speech-act. AUSTIN, J. How to do things with words. New York: Oxford University Press, 1975 (1954), p. 145.

${ }^{11}$ Isso ocorre porque, como reconhece Hintikka, a noção de inconsistência existencial não se aplica a todas as formas de proferimentos, mas apenas àquelas segundo as quais 0 papel do emissor é seminal para a compreensão do respectivo proferimento. HINTIKKA, J. Cogito ergo sum: inference or performance. In Critical Assessments, 1991, p. 162-185, p. 167.

12 HINTIKKA, J. Cogito ergo sum: inference or performance. In Critical Assessments, 1991, p. 162-185, 170.
} 
inconsistência existencial (expressa na impossibilidade a priori que o proferimento eu não existo tenha sucesso) conduz à intuição de que a existência quando posta na forma de um ato-de-fala - inscrito na primeira pessoa - é necessária por ser condição sine qua non da ação de proferir este enunciado.

\section{Problemas de ordem histórica na argumentação de Hintikka: o caminho para as Regras}

A seguinte passagem da Segundas Objeções é o coração de parte substancial dos argumentos de Hintikka sobre a rejeição cartesiana a uma leitura dedutiva do cogito, que abriria margem, segundo ele, à leitura performática:

Quando advertimos que somos coisas pensantes, trata-se de uma noção primeira, que não se conclui de nenhum silogismo; tampouco quando alguém diz ego cogito, ego sum, sive existo, deduz a existência a partir do pensamento por um silogismo, mas a reconhece por uma simples intuição como algo conhecido por si mesmo ${ }^{13}$.

Ainda que seja legítimo ler o proferimento eu existo como um ato ilocucionário, resta-nos saber se as justificativas históricas para uma leitura pragmática do cogito são peremptórias o suficiente para se obstar à leitura dedutiva deste argumento. Para justificar sua leitura Hintikka centra-se em dois argumentos: (a) ao negar o silogismo Descartes invalidaria qualquer leitura dedutiva do referido argumento (b) o caráter do intuitivo do cogito opõe-se diametralmente à sua transcrição em termos dedutivos. Esses argumentos merecem algumas observações quanto ao seu suposto lastro histórico.

a) Primeiramente, a negação do raciocínio dedutivo é associada no texto citado ao silogismo, per syllogismum deducit (AT, VII, p. 140/ AT, XI, p. 110), ao passo que, ao invés do que defende Hintikka, não encontramos em nenhum momento do texto uma afirmação de Descartes que desautorize o emprego da dedução para a compreensão do $\operatorname{cogito}^{14}$. A sua restrição ao emprego da dedução é circunscrita apenas ao silogismo, visto que se o argumento do cogito tem a pretensão de construir uma certeza sem partir de uma verdade preestabelecida, ele não pode aceitar uma premissa tal

${ }^{13}$ Cum autem advertimus nos esse res cogitantes, prima quaedam notio est, quae ex nullo syllogismo concluditur; neque etiam cum quis dicit, ego cogito, ergo sum, sive existo, existentiam ex cogitatione per syllogismum deducit, sed tanquam rem per se notam simplici mentis intuitu agnoscit. AT, VII, p. 140. De fato, caso estivesse na forma de um silogismo o argumento cartesiano teria a seguinte estrutura: Todo aquele que pensa existe (premissa oculta) / Eu penso / Logo eu existo. Essa forma de argumentação não aparece em nenhum texto cartesiano.

14 HINTIKKA, J. Cogito ergo sum: inference or performance. In Critical Assessments, 1991, p. 162-185, p. 165. 
como todos aqueles que pensam existem, requerida para completar o possível silogismo, sem antes verificar a facticidade do seu conteúdo. Neste sentido, a negação do silogismo não implica, como defendeu Hintikka, uma rejeição a toda forma de inferência, mas o reconhecimento de que a estrutura do silogismo, elaborado nas Segundas Respostas, considera como certa a premissa: aquele que pensa é, antes de justificá-la ${ }^{15}$.

Por conseguinte, parece-nos que a dedução silogística não é rejeitada na Segunda Objeção em função do seu apelo à inferência - o emprego da inferência será capital para o desenvolvimento de todas as Meditações mas porque a maneira como ela é construída permite um ganho quanto à validade formal ou lógica do raciocínio na medida em que o torna pouco informativo no que concerne à validade factual de suas premissas ${ }^{16}$. Em outras palavras, a recorrente crítica cartesiana ao silogismo não se assenta no fato de que ele necessite inferir uma coisa de outra, mas encontra-se, para usarmos as palavras de Descartes, na infertilidade do seu emprego, que ao invés de provar as premissas a partir das quais são construídas as suas deduções, considera-as como válidas apenas formalmente, em relação à sua estrutura lógica.

Assim, a conclusão, que está implícita nas premissas, termina não tendo nenhuma função informativa para o conhecimento a não ser pôr em evidência aquilo que foi tomado previamente como certo (Cf. AT, X, p.406 e AT, VI, p.17). Portanto, a intuição, mentis intuitu, aparece nas Segundas Respostas para enfatizar a impossibilidade de se submeter o enunciado ego sum, ego existo à forma de uma dedução sob a estrutura de um silogismo - o silogismo é estéril no que tange a produção do conhecimento metafísico - e não, como defende Hintikka ${ }^{17}$ para interditar uma constituição da certeza do cogito a partir de uma cadeia ordenada de implicações ontológicas. Desse modo, a passagem da negação do cogito enquanto consequência de um silogismo - afiançada por Descartes - para uma interdição de uma leitura dedutiva do referido argumento parece ser absolutamente apressada, imprópria ${ }^{18}$.

\footnotetext{
${ }^{15}$ Em carta a Clerselier o autor das Meditações reafirma o preconceito implícito na análise silogística: Contre le seconde Méditations, vos amis remarquent six choses. La première est qu'en disant: Je pense, donc je suis, l'auteur des Instances veulent que je suppose cette majeur: Celui qui pense est; et ainsi que j'aie déjà épousé un préjugé... (AT, IX, 205 // FA, II, p. 841).

${ }^{16}$ A disposição das Meditações repousa numa ordem dedutiva através da qual o conjunto das meditações só pode ser compreendida quando se põe uma em função da outra, segundo a ordem determinada no texto. Cf. AT, VII, p.4-5.

${ }^{17}$ HINTIKKA, J. Cogito ergo sum: inference or performance. In Critical Assessments, 1991, p. 162-185, p. 163.

${ }_{18}$ Talvez por isso Hintikka tenha atenuado sua rejeição a uma leitura inferencial do cogito em seu artigo subseqüente à publicação daquele que analisamos aqui. Cf. HINTIKKA, J. Cogito, Ergo Sum as an Inference and Performance. In The Philosophical Review, V. 72 n. 4, 1963, p. 487-496, p. 492.
} 
b) Quando indicamos na introdução do presente artigo a necessidade de uma volta às Regras para esclarecer a estrutura metodológica empreendida nas Meditações fora no intuito de desfazer alguns mal-entendidos que figuram na leitura de vários intérpretes do pensamento cartesiano, entre eles, o próprio Hintikka. Uma lacuna lapidar quando se interpreta as Meditações - subsequente à obliteração dos preceitos subscritos nas Regras - consiste na rejeição de uma leitura dedutiva do cogito, sob a alegação que Descartes teria afirmado que o referido argumento é objeto de uma intuição (argumentação que permanece no segundo artigo de Hintikka referente ao presente tema). De fato, Descartes reivindica nas Meditações a intuição como a forma de se adquirir a certeza da existência. Contudo, ao invés de negar o raciocínio dedutivo, a intuição compõe o raciocínio dedutivo, pois ela permite que se perceba imediatamente a concatenação entre os termos de um discurso. A seguinte passagem das Regras traça o ponto de interface entre os termos intuição e dedução:

Contudo, esta evidência e certeza da intuição não é requerida apenas para os enunciados, mas para qualquer discurso. Seja, p.ex., esta consequência: o resultado da soma de 2 mais 2 é o mesmo que o de 3 mais 1; não basta intuir que 2 mais 2 são 4 e que 3 mais 1 também são 4 . Mas, além disso, é necessário concluir destas duas proposições a terceira. ${ }^{19}$

A intuição além de abranger o conhecimento imediato, aplica-se ao ato discursivo através do qual diferentes proposições são articuladas na forma de um raciocínio. Neste sentido, pode-se conhecer por intuição uma cadeia de raciocínios como as igualdades matemáticas propostas no exemplo. $\mathrm{Ou}$ seja, uma determinada certeza pode ser dita de modo diferente, desde que se apresente, mediante um discurso, a rede de implicações que concorrem para sua composição. Essa perspectiva introduzida pelas Regras dissolve a forma disjuntiva (forte) de se conceber os termos intuição e dedução, desautorizando que se tome a afirmação cartesiana de que o argumento do cogito é objeto de uma intuição como uma rejeição à leitura dedutiva deste argumento, posto que é possível, segundo Descartes, intuir tanto a rede de implicações - exigida nas Meditações enquanto método de demonstração das verdades da metafísica e que concorre para instauração de uma determinada certeza - quanto essa mesma certeza tomada isoladamente. Assim, menos que duas operações diametralmente opostas - como parece defender Hintikka - intuição e dedução guardam uma íntima ligação; quase identitária ${ }^{20}$.

\footnotetext{
${ }^{19}$ At vero haec intuitus evidentia et certitudo, non ad solas enuntiationes, sed etiam ad quoslibet discursus requiritur. Nam, exempli gratia, sit haec consequentia: 2 et 2 efficiunt idem quod 3 et 1; non modo intuendum est 2 et 2 efficere 4 , et 3 et 1 efficere quoque 4 , sed insuper ex his duabus propositionibus tertiam illam necessario concludi. AT, X, p. 369.

${ }^{20}$ A diferença entre a intuição e dedução só poder ser constatada quando um dado raciocínio detém uma longa série de termos: Cf. AT, X, p. 89-90 e AT, X, p. 407-410.
} 


\section{O método de análise nas Meditações: as bases metodológicas para compreensão do argumento do cogito através da reductio ad absurdum}

A dissimulação do método empreendido nas Meditações não implica a diminuição de sua importância para a elaboração do texto. Os contemporâneos de Descartes não fizeram vistas grossas ao seu silêncio em relação ao método aplicado às Meditações, constrangendo-o a apresentar a via que ele seguira para ordenar o conjunto das seis meditações. Inicialmente Descartes limita a duas vias a maneira de demonstrar em metafísica: a razão de demonstrar é dupla: de uma parte por análise e de outra por síntese (Demonstrandi autem ratio duplex est, alia scilicet par analysim, alia per synthesim. AT, VII, 155). Se do ponto de vista contemporâneo a distinção entre o método de análise e o método de síntese é fortemente problemática, sobretudo no que se refere à fronteira que separaria esses dois métodos, Descartes considera essa distinção clara porque inscrita na dissimetria entre os dois únicos caminhos possíveis de se constituir uma demonstração: por um lado, a análise que ensina - exibe todas as implicações de uma cadeia de raciocínio - os passos da demonstração (esta é uma ótima via para ensinar / optima via est ad docendum. AT, VII, p.156). Por outro, a síntese que pressupõe axiomas e teoremas que não são ensinados porque são concebidos por definição, sendo, portanto, os princípios indemonstráveis de uma cadeia de raciocínio (nem satisfaz a aspiração dos que desejam aprender [entender], já que não ensina [explica] o modo como a coisa foi encontrada [como se chegou à conclusão]. / ...nec discere cupientium animos explet, quia modum quo res sit iventa non docet. AT, VII, p.156) ${ }^{21}$.

Dessas duas vias Descartes reconhece que empreendera a via analítica nas Meditações: ... quanto a mim segui apenas a via analítica nas Meditações [ego vero solam Analysim, (...) in Meditationibus meis sum sequutus. AT, VII, p. 156]. A escolha do método de análise justifica-se de uma dupla forma. Por um lado, de uma forma positiva, dada a meta de se apresentar o modo como foram conduzidos os passos da demonstração, sem omitir ou pressupor qualquer um desses passos, justificando, inclusive o caminho mediante o qual os referidos passos foram apresentados. Nesse sentido, ele pode ensinar como a demonstração foi realizada, visto que ele exibe a relação entre todas as variáveis - a ordem da sequência das proposições e o modo pelo qual elas estão ligadas - que concorrem para a instituição de uma determinada certeza. Por outro, ele pode ser justificado, de modo negativo, pela incompatibilidade do método de síntese com o objetivo das Meditações de não assumir nem um pressuposto - sejam eles axiomas,

${ }^{21}$ Nesse contexto traçado por Descartes, o termo ensinar (docere) porta a conotação de apresentar, no sentido de tornar visíveis os passos que conduzem a uma determinada conclusão. 
teoremas ou postulados - sem que esse pressuposto passe pelo crivo de uma demonstração (AT, VII, p. 1 e p. 4).

Como nas Meditações cumpre provar de forma clara e distinta as primeiras noções - tomadas pelo método sintético como axiomas (AT, VII, p.157) - o método de síntese é preterido por não apresentar a demonstração dos primeiros princípios, que são, segundo este método, por definição indemonstráveis. As Meditações requerem um método que possa tentar se desvencilhar de todos os conhecimentos preestabelecidos (AT, VII, p.17). Considerando que o método de análise permite uma construção de uma demonstração sem apoiála num axioma, Descartes parece reconhecer neste método uma ótima via para demonstrar os princípios fundamentais da metafísica, os quais ainda que sejam absolutamente conhecidos e verdadeiros, são passíveis de serem apresentados no que tange as implicações que eles mantém entre si.

Considerando ainda que o método de análise se impõe nas Meditações face ao método de síntese pela exigência de se apresentar todos os passos da demonstração ou implicações que financiam as certezas da metafísica, a proposta de uma leitura do cogito através do argumento da reductio ad absurdum ganha aqui consistência. Convém destacar inicialmente a compatibilidade entre o método analítico e a reductio ad absurdum.

O método analítico empreendido nas Meditações permite, segundo Descartes, o uso de hipóteses a partir das quais se considera uma determinada certeza como provisoriamente falsa. Ao recusar-se a discutir sobre questões estritamente ligadas à doutrina da Igreja, Descartes apresenta uma característica importante do modo de demonstrar analítico. É o que mostra, respondendo à objeção que teria negado os acidentes eucarísticos:

Nas Meditações eu supus ainda não os conhecer (acidentes), mas isso não significa que eles nada sejam. Com efeito, o modo analítico de escrever, que segui, permite que sejam pressupostas algumas coisas que ainda não foram suficientemente exploradas, como ficou claro na primeira Meditação, na qual tinha assumido muitas coisas que depois na continuação refutei ${ }^{22}$.

O epicentro da reductio ad absurdum repousa na aceitação de uma proposição verdadeira como falsa com a intenção de apresentar as contradições implicadas na não aceitação desta proposição como verdadeira ${ }^{23}$. Assim,

\footnotetext{
${ }^{22}$ In his vero Meditationibus supposui quidem ipsa nondum a me cognosci, sed non idcirco nulla esse; modus enim scribendi analyticus, quem sequutus sum, id patitur ut quaedam interdum supponantur quae nondum sint satis explorata, ut patuit in prima Meditatione in qua multa assumpseram, quae deinde in sequentibus refutavi. Nossa tradução (AT, VII, 249).

${ }^{23}$ Gaukroger sublinha que não apenas a reductio ad absurdum é uma forma de demonstração do método analítico para Descartes, mas que o método de análise permite compreendê-la como uma demonstração completa. Ela seria tão importante quanto a prova direta. Cf. GAUKROGER, S. Cartesian Logic: An essay on Descartes's conception of inference. New York/Oxford: Clarendon Press, 1989, p. 77.
} 
analisa-se (decompõe-se) as implicações dessa proposição, dada hipoteticamente como falsa - considerando a interdependência entre os fatores de uma sequência argumentativa como a legitimação da prova - a fim de atestar-lhe a veracidade mediante a apresentação da contradição que decorre de sua aceitação como falsa. Ao contrário da síntese, que parte sempre, segundo a concepção cartesiana, de definições, postulados, axiomas e teoremas (cf. AT, VII, p.156), a análise permite uma demonstração que inscreve os princípios da metafísica numa rede de implicações ontológicas mediante a qual eles podem ser apreendidos ordenadamente segundo os seus respectivos graus de prioridade; sem que o primeiro desses princípios esteja isento de demonstração.

Nesse sentido, podemos concluir provisoriamente que a reductio ad absurdum, por um lado, enquadra-se nas exigências do método analítico, por não pressupor diretamente axiomas. Por outro, ela servirá às Meditações graças ao fato de que através dela se pode tomar uma certeza (a existência) provisoriamente como uma proposição falsa - transcrita nas Meditações na afirmação da não existência daquele que pergunta sobre sua própria existência - cuja redução analítica (regressão) conduzirá a um absurdo, expresso na afirmação e negação do ato de pensar daquele que representa a sua não existência. Nessa perspectiva, apresentaremos uma leitura do argumento do cogito a partir da reductio ad absurdum.

\section{O cogito segundo a reductio ad absurdum}

Reverter o epicentro do conhecimento implicou na Primeira Meditação infringir certezas aparentemente inegociáveis. Contudo, a Segunda Meditação demarca o esforço de sanar os estragos epistemológicos da dúvida hiperbólica, cujo escopo fora capaz inclusive de comportar a dissuasão do sujeito da validade das proposições da matemática. Desse modo, a Segunda Meditação porta o ponto de inflexão que dissolve a incerteza - quase absolutizada pela dúvida hiperbólica - quanto à possibilidade do conhecimento claro e distinto para protocolar a primeira certeza do conhecimento metafísico: a certeza da existência de quem se concebe como não existente (AT, VII, p. 12-13).

Nessa perspectiva, a última dúvida que encerra a série de dúvidas exposta ao longo da Primeira e início da Segunda Meditação é relativa à existência daquele que se ocupa em estender a dúvida às últimas consequências. Assim, a dúvida acerca da existência daquele que duvida de sua própria existência traz consigo a forma da dúvida hiperbólica, exposta pelo artifício metodológico do gênio maligno. Contudo, ela, no plano das Meditações, insere-se no âmbito de uma tentativa de interromper o processo de dúvida a partir da constituição de uma primeira certeza. Ela é realizada 
apenas na Segunda Meditação, a partir da qual será instituída a primeira certeza transcrita na fórmula: eu sou, eu existo.

Assim, a dúvida de um sujeito relativa à sua própria existência detém um caráter metodológico cujo objetivo não é de destituir a certeza que nós temos sobre a nossa própria existência, mas é, conforme prescreve o método analítico, de rescrever essa certeza na forma de uma demonstração a partir da qual a nossa existência seja absolutamente inquestionável. Descartes declara nas Respostas às Objeções que se deve reconstituir a certeza do conhecimento a partir da certeza da existência:

Deve-se notar que ele [o objetor] confessa aqui que o início do filosofar, ou seja, o início da fundamentação de uma proposição segura, foi realizado por mim a partir do conhecimento da própria existência ${ }^{24}$.

Seguindo os preceitos do método analítico, Descartes não se abstém de construir uma prova para a existência, ainda que ela seja um pressuposto seminal à constituição de qualquer certeza. Ela é proclamada como o primeiro ponto a ser provado nas Meditações. Após permitir o acesso à dúvida hiperbólica (Primeira Meditação), as Meditações apresentam uma questão cuja dubitabilidade não pode ser transcrita senão de forma hipotética porque ela porta consigo uma certeza necessária à própria elaboração do texto. Nesse momento, emerge uma das questões nevrálgicas das Meditações: poderia não existir aquele que questiona sua própria existência? Porém, se a existência é um pressuposto para se questionar a própria existência, então como questioná-la?

O reconhecimento de um pressuposto, segundo a concepção cartesiana do método analítico, não lhe confere nenhuma prova. Caso esse reconhecimento fosse suficiente para lhe garantir uma prova, como no caso dos axiomas, a tentativa cartesiana de fundamentar todos os princípios do conhecimento por meio do método analítico, já teria falhado no primeiro deles $^{25}$. Porém, a questão persiste: é possível submeter esse pressuposto a uma prova por meio do método analítico?

A única forma de provar um pressuposto através do método analítico, apregoado por Descartes, é indireta, ou seja, supondo, per absurdum, que ele não seja necessário. Caso não seja necessário, não se trata de um pressuposto. A demonstração que está de acordo com as exigências às quais deve estar submetida a prova do cogito é a reductio ad absurdum. Essa

\footnotetext{
${ }^{24}$ Notandum est illum hîc fateri, initium philosophandi, sive initium firmae alicujus propositionis statuendae, a me factum esse a cognitione propriae existentiae... AT, VII, p. 480.

${ }^{25}$ Por isso as Meditações não podem ser consideradas um livro de demonstrações geométricas a partir de axiomas: Ce qui a été la cause pourquoi j’ai plutôt écrit des Méditations que des disputes ou des questions, comme font les philosophes, ou bien des théorèmes, ou des problèmes, comme les géomètres. AT, IX, p. 123 / AT. VII, p. 157.
} 
forma de demonstração mostra, com base numa suposição, a impossibilidade de se negar uma determinada tese. Assim, a reductio ad absurdum permite provar aquilo que é previamente concebido como certo sem necessariamente negar sua certeza. Ela apenas supõe sua falsidade a fim de demonstrar a contradição que se chega por meio dessa hipótese momentaneamente falsa.

A partir da dúvida que um sujeito lança sobre sua própria existência, expressa na hipótese de que ele não existe, pode-se reconstituir, tomando a não existência deste sujeito, que empreende aquela dúvida, como hipótese para a reductio ad absurdum, o argumento do cogito do seguinte modo: caso seja verdadeira, a representação de que eu não existo - expressa na pergunta derradeira antes da primeira certeza -, ela transcreve duas implicações ontológicas contraditórias; por um lado que eu não penso, posto que não existo ${ }^{26}$. Por outro, que eu penso posto que represento (concebo) a minha não existência. Assim, para que a representação da minha não existência possa ser válida, isto é, para que ela tenha um correspondente factual, o sujeito deve sempre assimilar uma contradição inscrita na dupla necessidade de pensar e não pensar quando pretende se conceber ou se persuadir como um ser não existente.

O conteúdo da representação da não existência de alguém que duvida da sua própria existência pressupõe, para que seja factual, duas certezas ontológicas necessárias, mas que, no entanto, são contraditórias e irreconciliáveis: 1) Esse indivíduo que representa a sua não existência não pensa (não duvida), posto que a facticidade do conteúdo da representação de sua não existência implica que ele de fato não exista e nem, consequentemente, pense. Ou seja, o gênio maligno (dúvida hipotética a respeito da própria existência) pode enganar o sujeito em todos os aspectos, mas para persuadir o sujeito de que ele não existe, seria necessário que o sujeito não pensasse, nem muito menos formulasse qualquer hipótese, inclusive a do gênio maligno. 2) Esse indivíduo que representa a sua não existência pensa (duvida), posto que concebe a sua própria não existência ${ }^{27}$. Por isso, por mais que alguém queira se persuadir de que não existe (ou que algum ser

${ }^{26}$ Deve-se tomar o termo representar no sentido original do latim (reapresento, as, are, avi, atum) conforme o qual ele designa a ação de colocar em evidência um certo objeto diante dos nosso olhos. Ou seja, representar a não existência significa conceber como objeto do pensamento a não existência. Não se trata, portanto, de se imaginar a não existência (conceber a não existência como uma imagem cuja raiz estaria numa certa psicologia cognitiva), mas de se considerar que a não existência de um indivíduo pensante não pode ser atestada mediante o seu próprio pensamento. Desse modo, não se trata de um limite psicológico - ligado à possibilidade de se imaginar a não existência - mas de um limite ontológico que não permite que se represente a não existência senão de forma contraditória.

${ }^{27}$ Colocamos entre parêntese o termo dúvida para acompanhar o termo pensamento, pois ele ainda não é concebido como consciência, mas apenas como ato de duvidar. A consciência é, sem dúvida, um pressuposto para a prova da existência ou ainda para certeza que se está duvidando, porém ela não é anunciada explicitamente no texto. Aliás, no 
hipotético queira o convencer disso) ele não pode conceber sua não existência senão assumindo a contradição (ou incompatibilidade) ontológica de que pensa ao se conceber como não existente e que ao mesmo tempo não poderia estar pensando posto que não existe. Desse modo, por mais que um gênio maligno tente enganá-lo, ele, enquanto se concebe como existente, deve existir: ego sum, ego existo, pois a afirmação contrária incorre numa contradição (incompatibilidade) ontológica expressa na simultânea afirmação e negação da atividade de pensar daquele que se considera existente.

A consciência de que pensa confere ao sujeito no Discurso a certeza de que existe (AT, IV, p. 32) ainda que todo o conteúdo do seu pensamento seja falso. Assim, no Discurso a dúvida sobre a certeza do conhecimento cessa quando se reconhece que ao pensar, independente da veracidade do conteúdo do pensamento - tudo pode ser falso - o indivíduo é necessariamente alguma coisa: ... eu gostaria de pensar que tudo fosse falso, mas deveria necessariamente reconhecer que eu, que penso, fosse alguma coisa ${ }^{28}$. Neste caso a formalidade (realidade formal) do pensamento, independente do seu conteúdo ou da informação que ele porta, implica a realidade efetiva daquele que pensa. Nas Meditações a dúvida não cessa pela consciência imediata da existência como pressuposto para o pensamento. Aliás, a seguinte justificativa, que se encontra na quarta parte do Discurso, desaparece completamente no texto das Meditações: senão que eu vejo claramente que para pensar é necessário existir (sinon que je vois très clairement que, pour penser il faut être (AT, VI, p. 33).

Nas Meditações a dúvida encerra quando o sujeito percebe que não pode se persuadir de que não existe, ainda que algum gênio maligno tente persuadi-lo dessa verdade: ... e por mais que engane, ele [o gênio maligno] nunca poderá fazer com que eu nada seja, enquanto eu pensar ser alguma coisa $^{29}$. A proposição eu sou, eu existo é certa porque é impossível, para qualquer indivíduo conceber a sua proposição inversa: eu não sou, eu não existo, como certa. Portanto, de todas as dúvidas aventadas ao longo das Meditações, uma delas não procede e tem um caráter apenas hipotético, como prescreve o modo de demonstrar analítico; aquela referente à existência do sujeito que tenta se persuadir quanto à sua não existência.

Considerando que é impossível para um indivíduo se persuadir de que não existe, a conclusão do argumento do cogito das Meditações não é je

Discurso a consciência é igualmente pressuposta, mas permanece implícita no raciocínio que conduz à proposição: penso logo existo. Convém salientar ainda que mesmo na definição do pensamento, que implica sentir, querer, duvidar, etc, a consciência permanece sem ser exibida ou discutida, sendo novamente pressuposta (AT, VII, p. 28).

${ }^{28}$... je voulais ainsi penser que tout était faux, il fallait nécessairement que moi, qui le pensais, fusse quelque chose. AT, VI, p. 32.

${ }^{29}$...et fallat quantum postest, nunquam tamen efficiet, ut nihil sim quandiu me aliquid esse cogitabo. AT, VII, p. 25. ... 
pense, donc je suis, ou ego cogito, ergo sum, pois a certeza da existência, ao contrário do que sugere o Discurso, não é tirada do fato de que o sujeito pensante não pode deixar de ser enquanto pensa; mas a conclusão do argumento do cogito nas Meditações põe em evidência a contradição implícita na representação da não existência daquele que pensa. $\mathrm{O}$ indivíduo tem certeza que existe não apenas porque pensa, mas, sobretudo, porque ele não pode provar ou demonstrar a sua não existência por meio do pensamento. Em suma, a conclusão do raciocínio não enfatiza o axioma próprio do modo de demonstrar sintético - expresso na certeza de que para pensar é necessário existir, mas analisa a afirmação do sujeito referente à sua própria não existência para concluir que tal afirmação é absurda, porque contraditória ${ }^{30}$.

Da diferença na estrutura do argumento do cogito, inscrita nos dois textos citados, segue-se o emprego de duas sentenças distintas para descreverem a certeza da existência. No Discurso o emprego de sentença: eu penso, logo existo confirma que a certeza do pensamento é condição necessária e suficiente pare se ter certeza da própria existência, posta a impossibilidade de que aquele que pensa nada, seja no momento em que duvida. Por outro lado, nas Meditações a conclusão eu sou, eu existo oferece-nos uma estrutura argumentativa diferente: embora a existência seja tomada sempre como um pressuposto para o pensamento, a sua prova é indireta e procede pela impossibilidade de o sujeito representar a sua não existência de maneira não contraditória (AT, VII, p. 12).

\section{Conclusão: $O$ argumento do cogito como uma prova \\ indireta}

A confusão entre os conceitos de ser e pensar no pensamento cartesiano, que dificulta a compreensão do método empreendido no argumento do cogito nas Meditações, acontece quando se comprime num mesmo argumento duas certezas que são distintas quanto à ordem das provas: primeiro, prova-se a contradição inerente à representação da não existência daquele que se concebe como não existente. Nas Meditações há um único conteúdo do pensamento que não pode ser posto em dúvida: a própria existência, isto é, enquanto pensa existir o sujeito não pode deixar de conceber sua existência (AT, VII, p. 25/linha 13). Segundo, prova-se que o pensamento é a substância - res cogitans - daquele que pensa, ou seja,

${ }^{30}$... ego sum, ego existo, quoties a me profertur, vel mente concipitur, necessario esse verum. AT, VII, p. 25. 
define-se que o sujeito pensante existe apenas enquanto pensamento, pondo em evidência a indissociabilidade do ato de pensar daquele de existir (AT, VII, p. 27) ${ }^{31}$. Desse modo, pensar implica a existência no que concerne à estrutura ontológica do sujeito, uma vez que no eu o ato de pensar e de existir são inseparáveis, mas no momento de provar a existência há dois passos - ligados, mas não idênticos - aquele que prova a existência do eu por meio da dúvida e outro que restringe a existência daquele que pensa ao próprio ato de pensar. Por isso, na ordem das provas não se pode, num primeiro momento, deduzir diretamente do pensamento a existência, pois ainda não se concebe o eu como uma res cogitans, cujo ato de pensar implica a existência. Contudo, pode-se provar a contradição de se conceber como certa a não existência daquele que pensa ou duvida da sua própria existência. Nesse sentido, a prova é indireta, pois não se parte apenas da certeza de que o pensamento implica a existência daquele que pensa, que estaria descrita na forma do axioma para se pensar é necessário ser, mas se demonstra a contradição (ou incompatibilidade) ontológica inerente à autorrepresentação da não existência.

O método de análise, até então negligenciado por parte importante da literatura especializada sobre o cogito, é transposto para as Meditações no intuito de prover a metafísica de uma argumentação que lhe confira uma primeira certeza que não esteja condicionada a um axioma cuja definição já implica indemonstrabilidade. Por isso, Descartes evitou usar a expressão nas Meditações: para pensar é necessário existir, construindo um argumento que analisa a contradição (ou incompatibilidade) ontológica expressa na aceitação da não existência de quem se concebe como não existente. $O$ método de análise é empregado, na forma da reductio ad absurdum, no intuito de demonstrar a contradição (ou incompatibilidade) ontológica inscrita na autorrepresentação da não existência e, portanto, a necessidade do enunciado ego sum, ego existo.

\section{Bibliografia}

ADAM, C. e TANNERY, P. (org.) Euvres de Descartes. 11v. 2ed. Paris: Vrin, 1986. ALQUIÉ, F. (org.) Euvres Philosophiques de Descartes. 3v. Paris: Garnier, 1973. ANDRADE M. DE OLIVEIRA, É. A Teologia negativa cartesiana. In Perspectiva Filosófica, v. II, 2006.

AUSTIN, J. How to do things with words. New York: Oxford University Press, 1975 (1954).

\footnotetext{
${ }^{31}$ Por isso a certeza da existência não implica que corpo e alma sejam separados, pois ela não apresenta a constituição ontológica do homem, ao passo que a certeza de que o sujeito é uma res congitans permite essa distinção, considerando que o homem pode ser concebido apenas como um ser pensante.
} 
GAUKROGER, S. Cartesian Logic: An essay on Descartes's conception of inference. Oxford, New York: Clarendon Press, 1989.

GUEROULT, M. Descartes selon l'Ordre des Raisons. 2v. Paris: Aubier, 1968.

FORLIN, E. O papel da dúvida metafísica na constituição do cogito. São Paulo: Humanitas, 2004.

HINTIKKA, J. Cogito ergo sum: inference or performance. In Critical Assessments, 1991, p. 162-185.

HINTIKKA, J. Cogito ergo sum comme inférence et performace. In Révue de Métaphysique et morale, n.1, 2000, p. 3-13.

HINTIKKA, J. Cogito, Ergo Sum as an Inference and Performance. In The Philosophical Review, v.72, n.4, 1963, p. 487-496.

HINTIKKA, J. Cogito ergo sum: inference or performance. In The Review of Philosophy, 1962, p. 50-65.

KANT, I. Crítica da Razão Pura. Lisboa: Fundação Calouste Gulbenkian, 1997.

Endereço do Autor:

Departamento de Filosofia

Av. Acad. Hélio Ramos, S/N $15^{\circ}$ andar

50670-901 Cidade Universitária - Recife - PE

ericoandrade@hotmail.com

44 Sintese, Belo Horizonte, v. 37, n. 117, 2010 